\title{
Communication processes and modern society
}

\author{
Olga Yu. Kornienko ${ }^{1}$, Tamara V. Naumenko ${ }^{1, *}$ and Olga S. Suvorova ${ }^{1}$ \\ ${ }^{1}$ Lomonosov Moscow State University, Faculty of Global Studies, 119991, Moscow, Russia
}

\begin{abstract}
The article targets specific features of modern economic and communication processes, the ones being most obviously revealed in such integral spheres of modern environment as social relations and service sector, as well as their connection with communicative space of today's social media. It focuses on ways to assess the role and place of mass-communication processes in optimization and development of social processes. It is conducted to ascertain the influence of major actors on modern society.
\end{abstract}

Modern epoch is the era of dynamic globalization processes and as such is closely impregnated with quickly developing innovative communication processes. The modern global economic environment integrates and intertwines practically all regional and national economies, which is to a great extent based on communication processes. The latter are now defining the structure, specific features and prospects of the current society.

The post-neoclassical stage of the present-day scientific development is focused on the subject of communication, it becoming the embodiment of the subject of communication, its object and the target goal of the social media development. It characterizes its great difference from the practices of all the previous stages. So, today the social sphere as well as the service sector acquires great importance in economic environment. These are the spheres to tackle not only production for a person as the subject of communication, but also they guarantee the quality of living standards and satisfy all his/her needs [1].

The analysis of the social sphere, not mentioning the service sphere, cannot be done without taking into account the communication network and telecommunications, as they represent a dynamically developing field of economy that shapes all the social and economic processes in modern society. From the structural point of view, telecommunication and communication networks are responsible for organizational and management type of activity in the society, it being an integral system, i.e. they lay down the foundations for organizational and communicational activities that manifest themselves in all other types of human activity and spheres of the society that result from them. Hence, we can detect some elements of communication and telecommunication in all forms and types of social relations. The telecommunication itself and the communication do not present any difficulty because of their clearly-set ontological definition and functional unambiguous expression. Besides, the information which is the major means for the realization of the above-mentioned functions is the main resource of post-industrial stage of society development, giving its very name to the society which is called an "industrial society". The phenomenon is the subject of study for many different sciences which leads to a very high level of comprehension in the scientific community, it embracing both the information itself and all other types of telecommunication on the whole [2].

However, the society structure entails one communication area which though similar to telecommunication is, nevertheless, absolutely different from it and presents quite a unique form of social activity. It implies mass-communication which is in the center of social sciences research and is called masscommunication. The challenge is in its close relation to telecommunication due to which the mass communication is often associated with telecommunication. This mis-association is not accidental, as both the mass communication and the telecommunication deal with information but they handle it differently. Telecommunication delivers information to inform the target audience and this is its major function, that is - the informational one. As for the mass communication, it implies the activity of impregnating into the mass consciousness the appraisal of phenomena and events which are topical from the point of view of the subject/agent currently in force. Hence, its function is to inculcate the appraisals and estimates in mass consciousness. In other words, the telecommunication broadcasts information related to events, phenomena and facts, while mass communication broadcasts information together with appraisals of events, phenomena and facts. Hence, on the one hand, the telecommunication has its primary function, that is to deliver information, and, on the other hand, acts as a form of mass communication. As for the mass communication, it looks like the process of broadcasting 
information in form, but in content, it is the activity of governing people's behavior through purposeful informational influence on mass consciousness. Besides, it contributes greatly to the formation of economic activity in social sphere and service sector by increasing their investment attractiveness [3].

In its external form mass communication, on the aggregate, is represented by mass media channels, such as printing media, radio and television. According to its internal form (content), it embraces all styles and genres of information delivery. Ordinary consciousness is unlikely to connect mass communication with the activity of inculcating appraisals of topical events. However, even when casting a casual glance at mass media activity, we cannot but notice that they give the public only the urgent information which is reviewed from the point of view of the social stance typical of that very information outlet, i.e. the information adjusted so as to shape the necessary assessment of the information. Furthermore, even the most unbiased mass media information, as it may look at first glance, in fact, contains factual assessments, which directly or indirectly entail the very choice of arguments and facts, the layout in press or time-mentioning while broadcasting [4] and etc.

There are lots of ways to produce an impact on the target reader, including lexical, lexico-semantical, syntactical and stylistic ones. Modern mass media is actively involving such lexico-semantical approaches as omission of important information in commercial as well as in political texts, mentioning in passing significant facts and events, making use of labels, such as "an aggressor", "power-hungry Putin" (during lectures of M. Galeotti, A. Brown at MSU and in the press). Another very important approach is to introduce a hypothesis at the beginning of a long text starting with the preamble, such as "Let's assume that". By the end of an advertisement or a political text the readers forget about the hypothesis and accept the information as presenting facts of real life.

Lexical methods are among the most popular ones. About a decade ago the American discourse started to actively use the word-combination "quantitative easing", thus avoiding such unpleasant shades of meaning as "early redemption of government bonds, for which the Fed launches the printing press." This is a euphemism and it produces even more soothing impression when the phrase is replaced by the abbreviation of QE. Abbreviations as such have no negative or positive connotations because the tints of meaning are included into the consonant structure of a word, but in case of abbreviations the consonant complex is omitted. The terms also give a great advantage to make the denotation obscure. When people listen to phrases with such words as "stock options, derivatives, futures," they understand that there take place most complex financial operations, but practically nobody appreciates that is means selling money for money, or cash equivalents or virtual equivalents by using most intricate schemes at the financial markets.

Another approach is to describe unpleasant facts or situations, using neutral or positive connotations. The
Americans at times use the phrase "fiscal cliff", which in reality means financial disaster, but the word "cliff" has no negative information, that of being at the verge of ruin. This approach as well as generalization of meaning helps to create better connotations. They become most actively used during the times of crises in economy and politics, which often gives a new life to English vocabulary. For instance, the USA started to often substitute a threatening word "crisis" by less negative words "downturn, turmoil, slump etc." during the financial crisis of 2008-2010.

One more approach is to streamline connotations by using polar meanings of synonymic rows. So, in case of showing your approval the term can be the "faith" with high positive connotation. When aimed at creating a negative assessment it is possible to use the word "fanatism".

Syntactical way of linguistic manipulation includes the use of interrogative and imperative constructions and short sentences to establish a dialogue-type communication with the audience. For example, one Lithuanian site [5] was involved into fund-rising and publish the following advertisement: "Last Year You Cut Everyone's Salary (except your own)? Donate a few litas to charity at aukoklt. You'll feel better." The real meaning implies: "You have stolen a lot? Donate! You will receive absolution!" In case you want to disguise information it is possible to use long, compoundcomplex structure and nominative constructions. The latter are widely popular nowadays, especially in the English language: power-happy, do-it-yourselfapproach, no-win-no-fee-contract etc. Lexicology welcomes the construction, though, in fact, they often make the meaning vague and do not give information about who-did-what.

Stylistic methods entail usage of metaphors, metonymy, meaning polarization. The latter draws special interest as it implies exactly the opposite. So, the phrase "active air defense", in fact, means "air raid", which is interpreted as "an active defense of air space", which is hardly traced form the word-combination "active air defense".

Multiple talk-shows, entertainment transmissions, jokes and stories about the lives of stars on the surface look destined for relaxation, not impregnated with evaluations and assessments, but in reality, they serve to draw people's attention to that or this mass media outlet. And secondly, they produce slacking, limping relaxing effect on mass audience, so that people are off their guards and easily appreciate the opinions and appraisals thrust on them. It brings our attention to the question why are the assessments and appraisals imposed upon us? And what is more, why is this fact concealed by those who are behind the scheme, while the public believes that the information is objective and unbiased? The answer is in the sphere of subject-object analysis of social and economic processes.

What is the aim of the actors in telecommunication? To be honest, their aim is nothing to do with higher information literacy of the population. Their major ambition lies in economic sphere and is aimed at getting profits. However, when we deal with mass 
communication, then we are to take into consideration that contrary to telecommunication it has poly-subject structure consisting of several levels, such as:

1) Social subjects who are interested in this or that type of influence on mass consciousness to change the people's behavior. They include: a) political interests to affect the electorate in order to gain or retain power; b) economic interests to create different needs, demands so as to stay competitive etc.; c) other interests which, in fact, also present either political or economic ones, though they can take the form ethnic, national, religious, ethical and other interests.

2) The actors, who are the owners of concrete mass media sources, are primarily the subjects of economic interests who are especially aimed at high economic returns on the information source in their possession.

3) Individual journalists working for mass media are responsible for creating information and because they develop their material for information consumers they become the agents of mass communication influence. However, they are not real agents of the mass communication influence as, first of all, they create texts and lay out materials according to the rules of the information policy defined by high-ranking actors and, secondly, they are only realization agents of their own professional and creative interests within this sophisticated hierarchy. The impression of independence and information freedom of a journalist results from two reasons: a) the journalist is lucky enough to share the information orientation of this mass media outlet; b) the journalist avoids the confrontation with information policy of the agency, channel, publishing house, notwithstanding his/her views. In fact, if the state of affairs is different, he/she would not continue working for the information outlet.

4. Mass audience itself is an actor demanding information about the environment which is necessary for adequate orientation in this environment. Thus, the mass audience constitutes the object-matter for the groups mentioned above, for while satisfying its needs of information the actors of mass-communication influence grant their own interests, either the political or the economic ones.

The poly-subjects structure of mass communication in conjunction with the asymmetry of interests of different social groups of the society in any of everexisting social structures leads to the situation when mass communication adjusts to the forms, characteristic of the corresponding period of the historical and socioeconomic development. Besides, it starts imposing on the mass audience the assessment of events, phenomena and processes that are relevant, meaningful and important for influencing stakeholders.

Modern mass communication has developed organizational and institutional forms, legal framework and a variety of creative ways of implementation. The economic processes are most obviously under a great influence of integrated marketing communications, such as advertising, public relations, marketing, branding, image-making, as well as journalists' creativity in laying out texts. The latter is to produce a necessary effect on mass consciousness in order to form a particular value system that will allow influencing the structure of consumer preferences of a mass audience [6]. As for the integrated marketing communications, they will affect not only the market sale but also the whole economic sphere of the society. This process is becoming more and more topical in the context of competitiveness when there is a great demand for the types of impacts on consumers, which affects the behavior of the mass audience unconsciously, and the latter guarantees high efficiency of such types of activity.

The main influence comes from public relations, though at times its importance is underestimated under the pretext that its aim is merely to establish relations with public. If advertising is an officially paid service to promote the goods or services, PR dissembles its persuasive role in economic relations. However, the very fact that in many countries, including Russia, there is a law banning the activities directed at creating a negative image (the so-called black PR), implies an enormous potential impact of this communication form both on political and economic life of the country. PR is intensively developing not only due to its masscommunication influence, but also thanks to other realization means. The former entails the fact that masscommunication influence is of primary importance as today the one who masters the mass consciousness, he owns the world. However, the other means are also important, mythologizing being just one of them. Myths' perpetuation by using all available tools has turned out to be one of the most effective ways to positively or negatively influence the competitive environment through mass-communication. It implies a variety of means: from spreading gossips to innovative approaches of promoting information, which are heavily impregnated with connotations for creating the target image for persons, goods, companies which can be done overtly or covertly. Secondly, modern PR uses a doublestage mass communication model. The whole point is that it is necessary to find out, or if necessary, to create an opinion leader which can be a person or a group of people that have indisputable authority among a particular target consumer audience. This PR move implies that properly trained opinion leaders are much more effective in their influence on the audience than the direct methods of mass-communication. Opinion leaders exercise their influence through mass media but it is done so that nobody suspects their involvement into PR campaigns and thus it does not lead to the refute of the information connotations.

Mass communication impacts all layers of modern society and all sophisticated structures, including even the state ones. Its impact can be taken into account while making the utmost state decisions, thus shaping financial, economic and political processes of the society. And what is more, the information warfare, that is widely discussed by policy-makers, is implemented by exclusively legal means, because the sophistication of forms and methods in modern mass-communication affects all social processes and public spheres and is advancing from year to year [7].

Taking into account all the above-mentioned, it is vitally important to state that improvement and 
sophistication of modern communication processes will have an influence on all industries in modern innovative economics, including the social sphere and services sector. The actors of the economic environment will be presented by the state, the private sector, but notwithstanding the stakeholders the ambition to impact the mass consciousness via telecommunication, will remain the priority as only such an influence guarantees multiple benefits from the economic activity of any organization

In the context of ever increasing globalization of social and economic space the integral influence of telecommunication and mass communication on mass consciousness is and will be on the rise, because in modern society no regimes and no actors will be able to get maximum positive results and will not be able to implement even most grand designs without an active support of the public and their active involvement in modern processes.

\section{References}

1. A.A. Auzan, The Economy of All Things. How institutes shape our life (Moscow, Mann, Ivanov, Ferber, 2014).

2. E.N. Zhiltsov, V.N. Kazakov, Economy of social industries in service sector (Moscow, High School, 2007).

3. K.Kh. Momdgan, Introduction into social philosophy (Moscow, High School, EH. University, 1997).

4. M.R. Solomon, Comsumers' Behavior (DiaSoftUp, 2003).

5. Absolution. Honest advertisements (Culturology RF, 2015), available online: URL http://www.kulturologia.ru/blogs/060711/14853/

(accessed on: 13.06.2015).

6. N.L. Smakotina, HP, 57, 091-095 (2012) [In Rus].

7. S.V. Semko, N.L.Smakotina, Tsennosti i Smysly, 21, 106-119 (2012) [In Rus]. 